\title{
Three Dimensional Two-Phase Flow Analysis of Tsunami Pressures and Forces Acting on a Building with Openings
}

\author{
HARTANA $^{1}$ and Keisuke MURAKAMI ${ }^{2}$ \\ ${ }^{1}$ Member of JSCE, Interdisciplinary Graduate School of Agriculture and Engineering, \\ University of Miyazaki (1-1 Gakuen Kibanadai Nishi, Miyazaki, 889-2192, Japan) \\ E-mail: na11007@student.miyazaki-u.ac.jp \\ ${ }^{2}$ Member of JSCE, Associate Professor, Dept. of Civil and Environmental Engineering, University of Miyazaki \\ (1-1 Gakuen Kibanadai Nishi, Miyazaki, 889-2192, Japan) \\ E-mail: keisuke@cc.miyazaki-u.ac.jp
}

\begin{abstract}
Hydraulic interactions between tsunami flow and structures located along coastlines include quite complex phenomena, because the tsunami flow acts on a structure with trapping air. In order to design structures such as an evacuation building properly, it is important to consider the effect of this entrapped air in the investigation of tsunami hydrodynamic loads. This study is aimed at investigating the characteristics of tsunami hydrodynamic loads on multi floor buildings with openings by using a two-phase flow model in a three dimensional space. Two types of building models, the building with openings and the building without openings, were examined in this study. Numerical results were compared with the results obtained from one-phase flow simulations, and also verified with the experimental ones. The numerical results obtained from the two-phase flow model show good agreement with the experimental results. Furthermore, the two-phase flow model simulates the interface between water and air inside the building more accurately than the one-phase flow model. The openings in the building reduce the sustained pressure acting on the front side. The effects of the opening ratio and entrapped air to the wave pressures and uplift forces acting on the floor slab were also discussed.
\end{abstract}

Key Words: Two-phase flow, bore type tsunami, entrapped air, uplift force, building with openings

\section{INTRODUCTION}

Indian Ocean tsunami in December 2004 and Tohoku earthquake tsunami in March 2011 had been considered as the recent worst natural disasters. Those tsunamis have brought severe damages on infrastructures and extensive economic losses. The catastrophic casualties caused by those tsunamis demonstrated the need of safety evacuation in tsunami prone areas in order to minimize loss of human lives. The basic principle in mitigating tsunami disaster is the evacuation to higher ground above the tsunami inundation zone, or a reliable evacuation building which has higher floor than tsunami inundation level.

Tsunami potentially produces large hydrodynamic loads on the structures. The physical understanding of hydraulic interactions between tsunami and structures located on coastal area is quite important in designing structures such as evacuation buildings. Especially, tsunami exerts on the structures with entrapping air, and the air sometimes plays an important role in the characteristic of hydraulic forces. Based on above background, it is important to consider the effect of this entrapped air in the investigation of tsunami hydrodynamic loads acting on structures ${ }^{1)}$.

This study conducted two-phase flow analysis in three dimensional space to investigate the hydrodynamic loads on multi floor buildings with considering the effect of the entrapped air. A three-story building with openings was considered as the model structure, where the openings mean the windows. This kind of building can be seen in the public school that is occasionally designated as an evacuation building.

A series of physical experiments were conducted to confirm the validity of the results obtained from numerical simulations. One-phase flow simulations were also conducted to discuss the difference of numerical results between the two-phase flow model and one-phase flow one. 


\section{MODEL SETUP}

\section{(1) Hydraulic experiment}

The experiments were conducted in a two-dimensional open channel flume with $12.0 \mathrm{~m}$ in length, $0.4 \mathrm{~m}$ in width and $0.4 \mathrm{~m}$ in depth. Fig.1 describes the schematic of experimental setup. The model scale was 1/40. A slope with 1:40 was installed in the flume, and a flat section, $0.05 \mathrm{~m}$ above the bottom, was set behind the slope.

The building model was rigidly mounted on the center of the flume at the distance $6.8 \mathrm{~m}$ from the gate. The configuration of this hydraulic experiment means that each building is set $0.4 \mathrm{~m}$ interval perpendicular to the flume centerline.

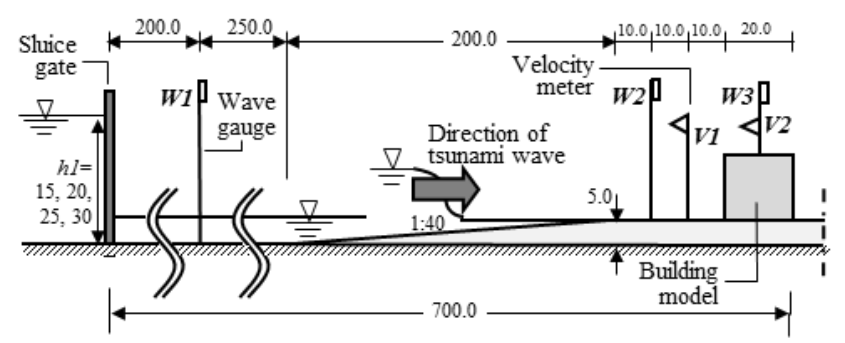

(a) Side view (unit: $\mathrm{cm}$ )

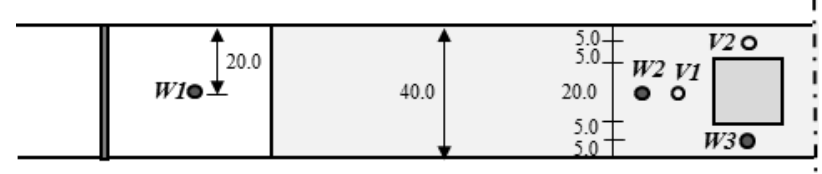

(b) Plan view (unit: $\mathrm{cm}$ )

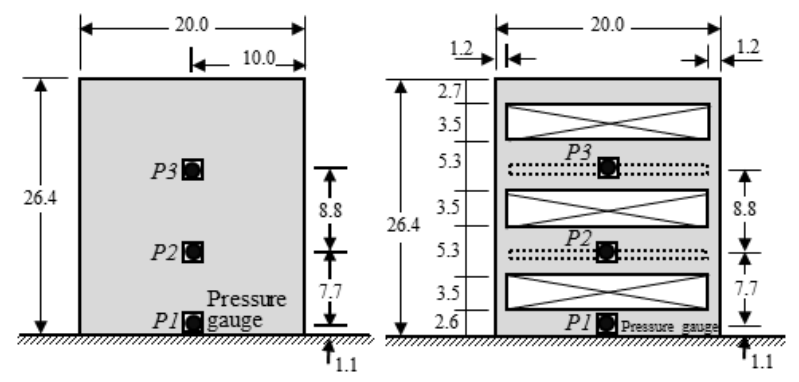

Without openings

With $40 \%$ opening

(c) Location of pressure gauges on front side (front view, unit: $\mathrm{cm})$

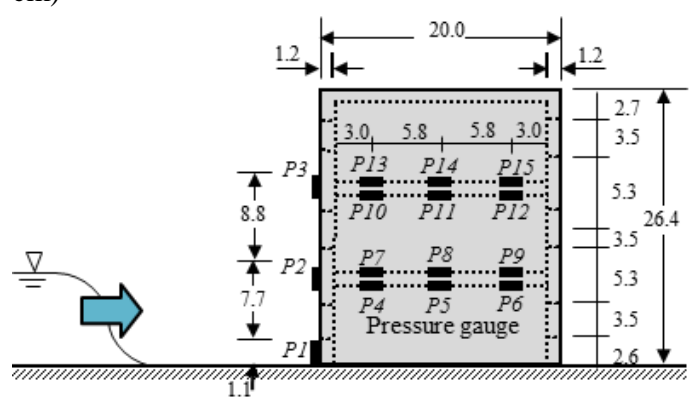

(d) Location of pressure gauges inside the building with $40 \%$ opening (side view, unit: $\mathrm{cm}$ )

Fig.1 Experimental setup
Journal of Japan Society of Civil Engineers, Ser.

B3 (Ocean Engineering), Vol. 70, No. 2, I_450-I_455, 2014.

Bore type tsunamis with different height were generated by instantaneously lifting up a sluice gate which was equipped on the upstream of the flume. This generation scheme is the same as a dam break phenomenon, and this method can realistically simulate the turbulent hydraulic bore waves ${ }^{2}$. The gate initially separated a volume of impounded water from the water on downstream side. The impounded water depth behind the gate was set as $h_{l}=15 \mathrm{~cm}$, $20 \mathrm{~cm}, 25 \mathrm{~cm}$ and $30 \mathrm{~cm}$. The water depth at the downstream area was maintained as $0.05 \mathrm{~m}$.

The shape of the building models was the square column of $20 \mathrm{~cm} \times 20 \mathrm{~cm}$, and its height was $26.4 \mathrm{~cm}$. Two configurations of three-story building models, one was the solid building without openings (Fig.1(c)) and the other was the building with openings (the right of Fig.1(c) and Fig.1(d)), were examined in this study. The building with $40 \%$ openings on the front and rear walls was investigated in the experiments. The building model was made of wood with $1.2 \mathrm{~cm}$ thickness, and the side panel was made of acrylic in order to check the flow inside the building.

Three pressure gauges $(P 1-P 3)$ were attached along the vertical centerline on the front face of the building model as shown in Fig.1(c). While pressures on the ceiling and floor in each story of the building with openings were recorded with twelve pressure gauges (P4-P15) which were set every $0.058 \mathrm{~m}$ interval along the horizontal centerline on the floor and ceiling as shown in Fig.1(d).

The time history of water surface elevation was measured at the propagation area and inundation one. A wave gauge at $W 1$ located $2.0 \mathrm{~m}$ from the gate recorded the incoming wave profile, while two wave gauges (W2 and W3) were placed at the inundation area around the structure. Two propeller current meters ( $V 1$ and $V 2$ ) measured fluid velocity in front of and side of the structure. The measured data were recorded with using a data acquisition system. The sampling rate was $0.001 \mathrm{~s}$ in this study. The measurements for each case were conducted three times in order to check the errors in the experiments.

\section{(2) Numerical model}

Two kinds of numerical model were used to investigate the hydraulic forces acting on the building model under tsunami bore impact. This study employed OpenFOAM v.2.1.1 as a two-phase flow model in three dimensional space, and also employed CADMAS-SURF/3D as one-phase flow model. Both models solve Navier-Stokes equations and continuity one, and employ Volume of Fluid (VOF) method to track the free surface deformation $^{3,4)}$. CADMAS-SURF model applies finite difference method with a staggered grid mesh, 
whereas OpenFOAM uses finite volume method. The no-slip boundary condition on the interface between fluid and a solid body was applied in this study.

The anisotropic structured numerical grids in $x$ and $z$ dimensional field were taken in the range from $1.8 \mathrm{~cm}$ to $0.6 \mathrm{~cm}$ in hexahedral elements. Whereas, a homogeneous grid was applied in $y$ axis as $\Delta y=0.6 \mathrm{~cm}$ throughout the domain. The finer mesh with minimum cell size was utilized in the vicinity of building model. In order to satisfy the numerical stability, the Courant Number was assigned below 0.5 in model computation.

The numerical simulation was performed to investigate the hydraulic properties under the bore type tsunami acting on the buildings which was configured as the experimental setup. The upstream input boundary of the numerical wave tank was set at the location of the water surface elevation gauge at Wl in the experiments. The time histories of water surface elevation and fluid velocity were prescribed as inflow properties on the face of input boundary in order to generate a bore type tsunami. These values were uniformly assigned on the ghost cells, which were set outside of the upstream cells. The time history of wave profile obtained from the experiment at $W 1$ was applied on the input boundary. The fluid velocity was calculated based on an analytical equation derived by Fukui ${ }^{5,6}$. This equation formulates a relation between water surface displacement and mean fluid velocity for the propagation of bore type tsunami wave.

\section{SIMULATED RESULTS ON THE BUILDING WITHOUT OPENINGS}

\section{(1) Tsunami inundation}

Fig.2 and Fig.3 show the profiles of water surface elevation and fluid velocity in the cases of building without openings. Gradual increase can be seen in the results of water surface elevation, and also the rapid increase can be seen in the velocity profiles. After these increasing phases, water surface profile and velocity one maintain a certain level as a sustained phase depending on the incident wave height. The maximum sustained water surface elevation appears around 2.0-3.0 seconds after the increasing phases.

In above sustained phase, the results obtained from the one-phase flow model and two-phase flow model fit the measured results fairly well in water surface elevation and velocity. On the other hand, the results obtained from both numerical models slightly overestimate the measured ones at each increasing phase. The numerical results of sustained velocity beside the structure appear to slightly lower than the experimental ones.
B3 (Ocean Engineering), Vol. 70, No. 2, I_450-I_455, 2014.

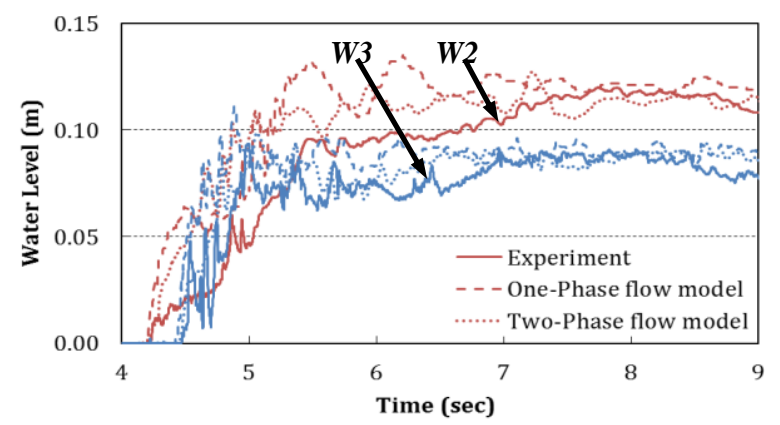

Fig.2 Water surface elevations at $W 2$ and $W 3$ in the case of tsunami height $H_{l}=6.64 \mathrm{~cm}\left(h_{l}=20 \mathrm{~cm}\right)$

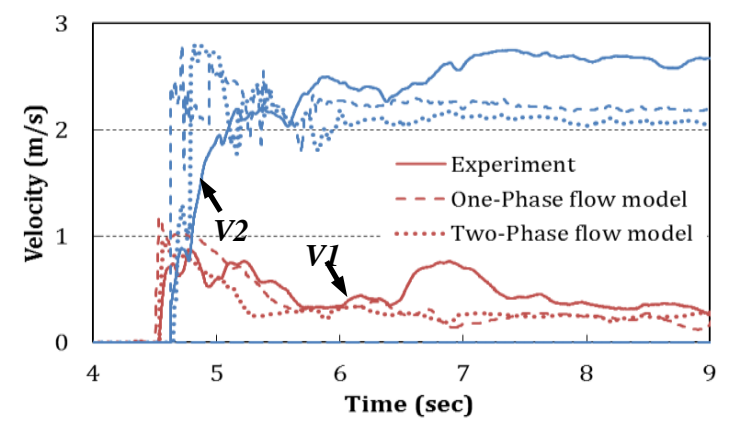

Fig.3 Velocities profile at $V 1$ and $V 2$ in the case of tsunami height $H_{l}=6.64 \mathrm{~cm}\left(h_{l}=20 \mathrm{~cm}\right)$

\section{(2) Pressure profile}

Fig.4 shows the time history of pressure at $P 1, P 2$ and $P 3$ obtained from the experiment and numerical simulation in the cases of building without openings. In this figure, the wave pressures were normalized by the hydrostatic pressure, $\rho g h$, where $h$ means the bore height resulted from the $20 \mathrm{~cm}$ impounded depth in the absence of the building model.

An impulsive pressure followed by sustained one can be observed at $P 1$ and $P 2$. The pressure at $P 3$ did not show the impulsive pressure in both measurement and simulations, because this location was slightly higher than the maximum inundation level. The maximum sustained pressures can be seen around 3.0-3.5 seconds after the impulsive pressures. The differences between the one-phase flow results and two-phase flow ones are small in front of the structure, and the results of both simulation models show good agreement with the measured data.

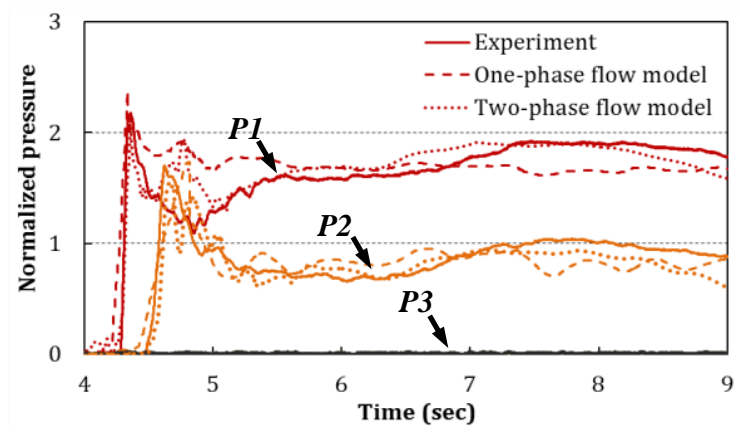

Fig.4 Pressure profile on the front side of building without openings in the case of tsunami height $H_{l}=6.64 \mathrm{~cm}$ $\left(h_{1}=20 \mathrm{~cm}\right)$ 


\section{SIMULATED RESULTS ON THE BUILDING WITH OPENINGS}

\section{(1) Effects of openings on tsunami inundation}

Fig.5 shows the water surface elevation at $W 2$ obtained from experiment and numerical simulations in the case of building with $40 \%$ opening. The results in the case of building without openings are also drawn in this figure.

The opening on the building allows the flow through the structure, and it lowers the sustained water surface elevation in front of the structure in comparison with the case without openings. The better agreement can be seen between measured results and computed ones from the two-phase flow simulations.

Fig.6 compares the profiles of fluid velocity, $V 1$, located at $10 \mathrm{~cm}$ in front of the model in the case of building with $40 \%$ opening. The results in the case of building without openings are also presented in this figure. The velocity profile obtained from numerical simulations shows fairly good agreement with the experimental ones. In the case of building with openings, the tsunami bore passes through the openings on the structure. Thus, the tsunami flow in front of building with openings attains higher velocity.

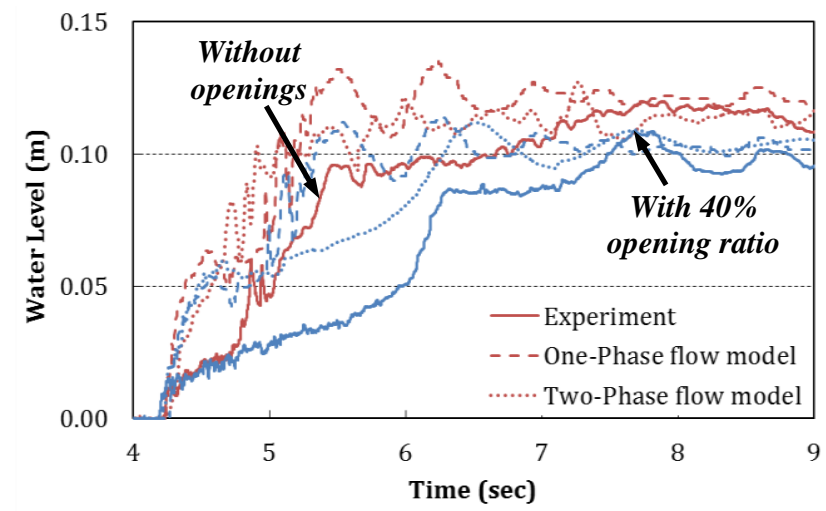

Fig.5 Water surface elevations at $W 2$ in the case of tsunami height $H_{l}=6.64 \mathrm{~cm}\left(h_{l}=20 \mathrm{~cm}\right)$

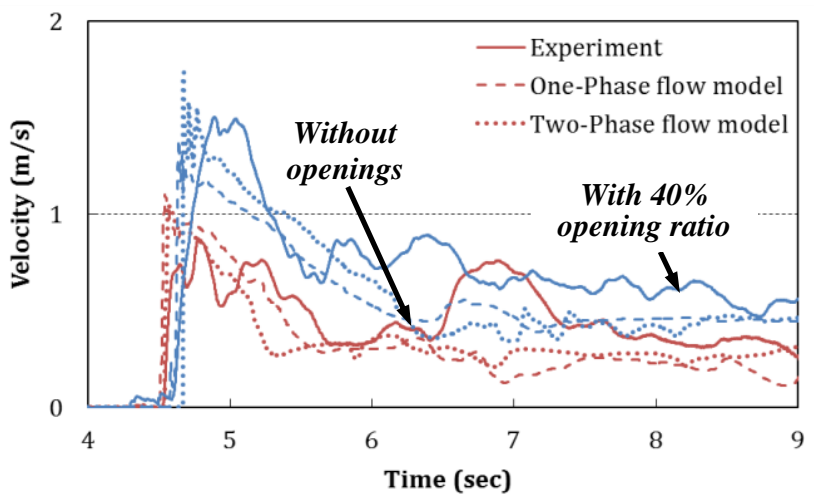

Fig.6 Velocities profile at $V 1$ in the case of tsunami height $H_{1}=$ $6.64 \mathrm{~cm}\left(h_{l}=20 \mathrm{~cm}\right)$

\section{(2) Effects of openings on pressure acting on the front face of building}

Fig.7 shows the pressure profiles acting on the front face of the building with $40 \%$ opening. The pressures in the case of building without openings are also included in this figure. The results of two-phase model show good agreement with the experimental results. In addition, the openings in the building tend to reduce the maximum sustained pressure on the front face of the structure. It is because the openings in the building reduce the inundation depth in front of the building.

\section{(3) Characteristics of flow inside the building}

Fig. 8 shows the snapshot of tsunami inundation in the building with $40 \%$ opening. The left side photos show the images of experiment, others are obtained from numerical simulations. In OpenFOAM snapshots, red color corresponds to the water, blue represents air, and other colors denote the interface between water and air.

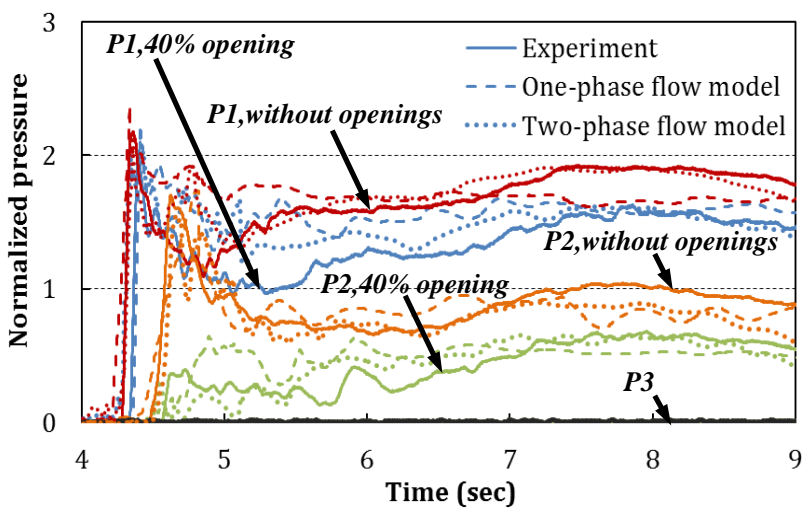

Fig.7 Pressures on the front face of building in the case of tsunami height $H_{l}=6.64 \mathrm{~cm}\left(h_{l}=20 \mathrm{~cm}\right)$
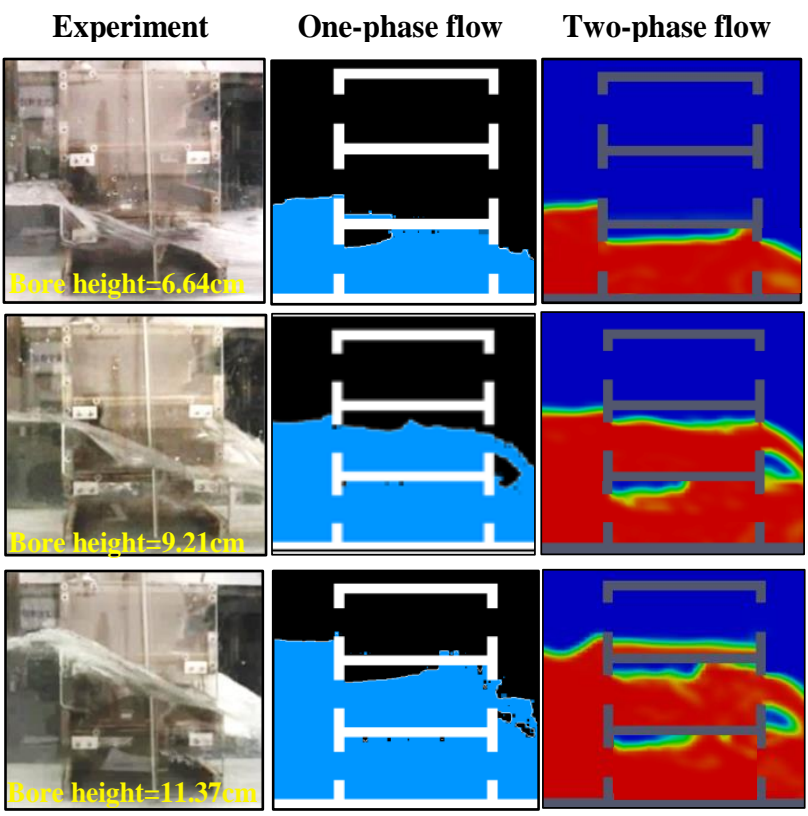

Fig.8 Snapshots of tsunami inundation on the building with $40 \%$ opening at $t=7 \mathrm{~s}$ 
Both numerical models were able to predict water surface profile around the building. However, the results obtained from the two-phase flow simulations show better qualitative similarities with the experimental data in predicting the flow inside the building. The entrapped air was formed beneath the floor slab both in hydraulic experiments and two-phase flow simulations when the tsunami wave makes a contact with the floor slab. This entrapped air exists during the submergence of the lower floor slab by the tsunami flow.

\section{(4) Effects of entrapped air on pressure acting on the floor slab}

Fig.9 presents the profiles of fluid pressure acting on the front section of the floor slab on the ceiling $(P 4)$ and the floor (P7), in the case of tsunami height is $9.21 \mathrm{~cm}$. An impulsive pressure can be seen on both profiles. These impulsive pressures were followed by the continuous sustained pressure with fluctuations. These fluctuations are due to the complex action of tsunami flow inside the building.

At $P 4$ and $P 7$, the pressure obtained from the two-phase flow model shows fairly good agreement with the measured pressure in comparison with the result from one-phase flow model, though the simulation result at $P 7$ shows slightly overestimates in the increasing phase. On ceiling and floor, the one-phase flow model overestimates initial impact pressure and sustained one. The entrapped air reduces the pressure magnitude due to its cushioning effect ${ }^{7)}$, and this effect caused the discrepancy of one-phase flow model at $P 4$ where the entrapped air is formed.

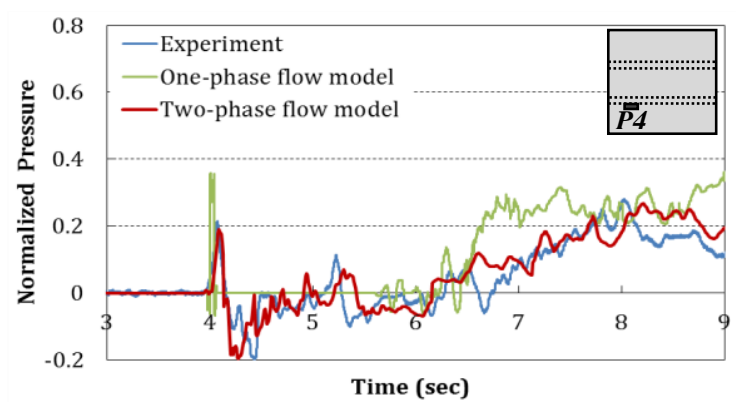

(a) $P 4$

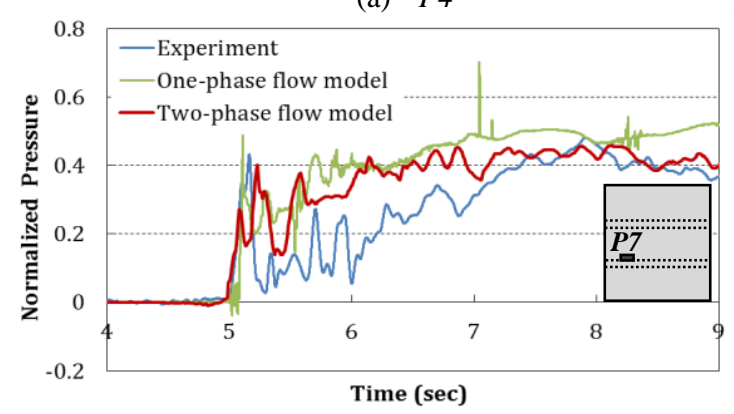

(b) $P 7$

Fig.9 Pressure profile at $P 4$ and $P 7$ in the case of tsunami height $H_{l}=9.21 \mathrm{~cm}\left(h_{l}=25 \mathrm{~cm}\right)$
Journal of Japan Society of Civil Engineers, Ser.

B3 (Ocean Engineering), Vol. 70, No. 2, I_450-I_455, 2014.

In Fig.9, the results obtained from one-phase flow simulations show some pressure spikes. These spikes were assumed to be caused by the effect of the rapid transition of the used labeling method in one-phase flow simulations ${ }^{8}$. The pressure has to achieve the mass conservation in the created fluid cells due to the rapid transition of the changing cell labels from the empty cells and surface cells to fluid cells. In one-phase flow simulations, the pressure manifests itself in a spike pressure. This spiky pressure can be prevented in two-phase flow simulations, because two-phase flow model applies mass conservation to the empty cells and surface ones.

\section{(5) Effects of opening ratio on pressure and vertical force on the floor slab}

In this section, the characteristic of pressure on the building are investigated on the OpenFOAM simulations. In order to understand the effect of the opening ratio on pressures and forces acting on the buildings, the opening ratio on the building model was changed as 50\% and 60\%. As shown in Fig.10, the upper walls beneath the slab on each floor are fixed in this study.

Fig.11 presents the distribution of sustained pressure acting on buildings at $t=7 \mathrm{~s}$ in the case of tsunami heights are $9.21 \mathrm{~cm}$ and $11.37 \mathrm{~cm}$. The pressure increases with the increase of incoming tsunami height. The pressures acting on the floor were slightly larger than that on the ceiling.
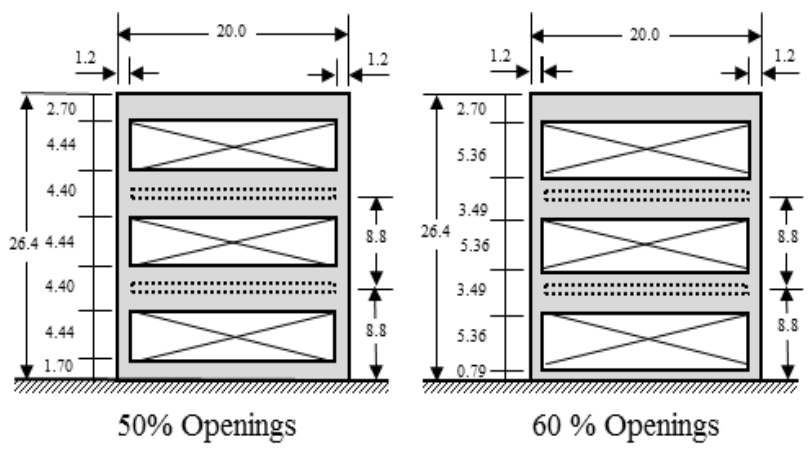

Fig.10 50\% and 60\% opening ratio configuration
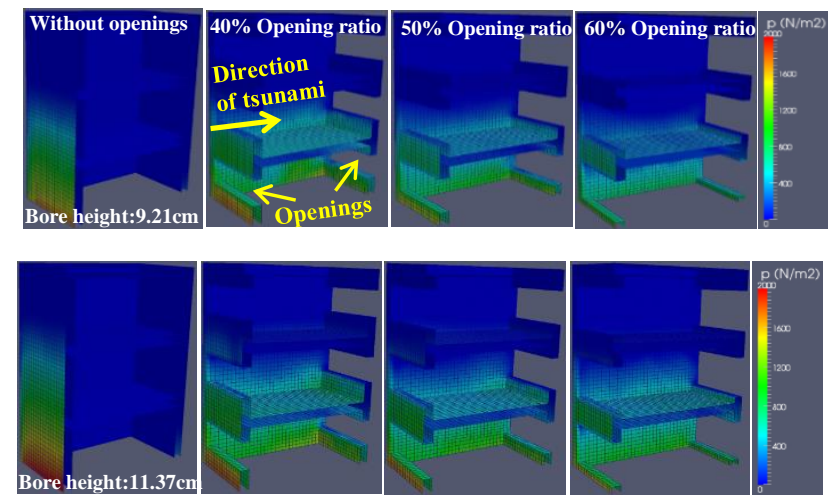

Fig.11 Pressure distribution on the building models at $t=7 \mathrm{~s}$ 
It can be found that the difference of opening ratio influenced the magnitude of pressure on the floor slab. The larger opening ratio tends to reduce pressure acting on the floor and the ceiling. It is because the larger opening ratio decreases the inundation depth around the structure under the continuous tsunami flow into the building. The reduction of pressure acting on the floor in the case of larger opening ratio is also caused by the shallower water depth contained by the walls beneath the openings, and this decreases the magnitude of hydrostatic pressure.

Fig.12 compares the uplift force acting on the lower floor slab on various opening ratios. The normalized force is obtained by integrating the normalized pressure $(p / \rho g h)$ over the surface of upper side and underside of the floor slab. The uplift force is characterized by a rapid increase of initial upward force with short duration followed by the downward sustained force. The larger opening ratio tends to take slightly longer time on achieving the peak of initial uplift force.

The larger opening ratio tends to reduce the magnitude of initial uplift force acting on the floor slab. It is because the front walls change the flow pattern inside the building. In the case of tsunami force acting on the structures with concave shape such as a bridge structure with girders, the tsunami flow turns its horizontal direction to upward, and this changes the horizontal momentum to the vertical one $^{9)}$. The change of the tsunami flow direction in the case of building with openings occurred at the edge of upper front wall, as shown in Fig.8. In the case of smaller opening ratio, the higher front wall beneath the openings caused the change of flow direction from horizontal to upward direction largely, and this increase the magnitude of initial uplift force. Furthermore, the larger opening ratio tends to reduce the downward sustained force acting on the floor slab due to the lower magnitude of pressures acting on the floor.

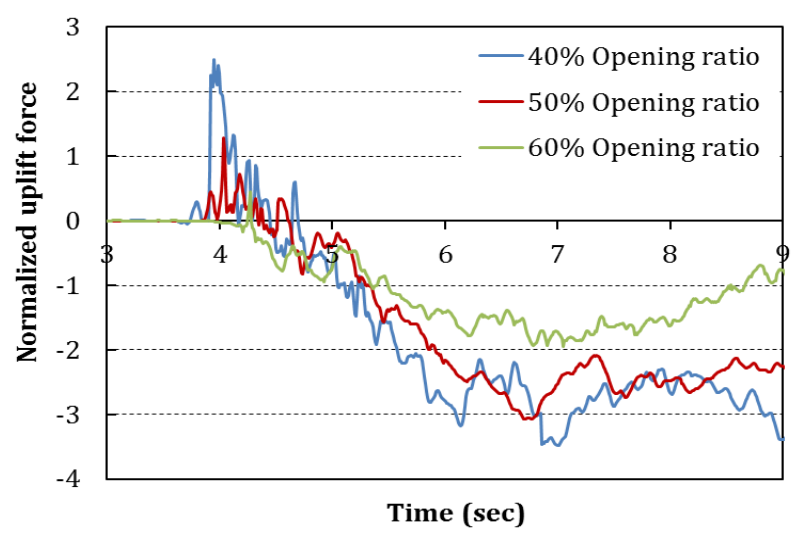

Fig.12 Uplift force acting on the slab in the case of tsunami height $H_{l}=9.21 \mathrm{~cm}\left(h_{l}=25 \mathrm{~cm}\right)$

\section{CONCLUSIONS}

A two-phase flow model, OpenFOAM, was applied to investigate the dynamic pressure and force acting on buildings in the case of structure with openings and without openings. The building with openings and the building without openings were examined. Simulation results were compared to the results obtained from one-phase flow simulations, and verified by comparison with the experimental results.

Numerical results obtained from the two-phase flow model show good agreement with the experimental results. The differences of numerical results between one-phase flow model and two-phase flow one are small in the case of building without openings. On the other hand, the differences become larger in the case of building with openings. The two-phase flow model simulates the interface between water and air inside the building better than one-phase flow model.

The openings in the building reduce the sustained pressures on the front side of building. Furthermore, the larger opening ratio tends to decrease the pressure acting both on the floor and the ceiling. The difference of opening ratio influenced the magnitude of vertical force on the floor slab. The larger opening ratio reduces both the impulse uplift force and maximum downward sustained one on the floor slab.

\section{REFERENCES}

1) Federal Emergency Management Agency: Guidelines for Design of Structures for Vertical Evacuation from Tsunamis, FEMA, http://www.fema.gov/library/viewRecord.do?id=3463, 2008.

2) Yeh, H., Ghazali, A. and Marton, I.: Experimental Study of Bore Run-up, J Fluid Mech, Vol.206, pp. 563-578, 1989.

3) Coastal Development Institute of Technology: CADMAS-SURF/3D Research and development of numerical wave tank, Coastal Technology Library, No.39, 235 pp., 2002.

4) Open CFD: OpenFOAM 2.1.1-The Open Source CFD Toolbox User Guide, Open CFD, Ltd., 68 pp., 2012.

5) Fukui, Y., Hidehiko, S., Nakamura, M. and Sasaki, Y.: Study of tsunami -Investigation of wave velocities in case of bore type tsunami-, Annual Journal of Coastal Eng. in Japan, Vol. 9, pp. 44-49, 1962 (in Japanese).

6) Wijatmiko, I. and Murakami, K.: Numerical simulation of tsunami bore pressure on cylindrical structure, Annual Journal of Civil Eng. in the Ocean, JSCE, Vol. 26, pp.273-278, 2010.

7) Hartana and Murakami, K.: 2-Phase Flow Analysis of Tsunami Forces Acting on Bridge Structures, Annual Journal of Civil Engineering in the Ocean, JSCE, Vol. 69, No.2, pp.347-352, 2013.

8) Wemmenhove, R., Loots, G.E. and Veldman, AEP.: Numerical simulation of hydrodynamic wave loading by a compressible two-phase model, Proc. of ECCOMAS CFD 2006, Delft, Netherland, pp.1-13, 2006.

9) Hartana and Murakami, K.: Experimental Study on Tsunami Hydraulic Forces Acting on a Bridge Structure, Proc. of Int. Sessions in Coastal Eng., JSCE, Vol. 4, pp.55-59, 2013. 